Article

\title{
The Development and Properties of the Support Needs Questionnaire
}

\author{
Fabian A. Davis ${ }^{1, *}$ and Jan Burns ${ }^{2}$ \\ ${ }^{1}$ Department of Clinical Psychology, Oxleas NHS Foundation Trust, SE20 7TS Penge, London, UK; \\ E-Mail: 100255.3512@compuserve.com \\ ${ }^{2}$ School of Psychology, Politics and Sociology, Canterbury Christ Church University, CT1 1QU, Kent, UK; \\ E-Mail: jan.burns@canterbury.ac.uk \\ * Corresponding author
}

Submitted: 3 November 2014 | In Revised Form: 9 April 2015 | Accepted: 10 April 2015 |

Published: 24 July 2015

\begin{abstract}
The Support Needs Questionnaire (SNQ) measures the support people with severe mental illness need to attain valued social roles as a route to social inclusion. Its design derives from Wolfensberger's Social Role Valorisation theory. It is a clinical tool comprising a comprehensive lifestyle inventory of "universal basic" and "disability" needs; and "revalorisation needs" arising from social devaluation and deep exclusion. The SNQ comprises eight discreet sub-scales based on O'Brien's Five Service Accomplishments, the domains of which include Community Presence, Community Participation, Choice and Control, Social Roles and Respect, Skills and Competencies, and Finance. There are also two descriptive subscales: Physical and Mental Health. The item set was developed collaboratively with service users. This paper introduces the SNQ, its design rationale and development, and investigates aspects of its reliability, validity and utility. Care coordinators in a Community Mental Health Team rated eighty-two service users' support needs at a two week interval using the SNQ, the Global Assessment Scale and the MARC-2. The SNQ is shown to have high test-retest reliability, good construct and concurrent validity, and good discriminatory power. It exhibited no floor or ceiling effects with the reference population. It could be used with a more diverse population. The descriptive sub-scales were weakest. The population profile showed moderate support was required for physical integration but high levels for social integration which is consistent with previous research. The SNQ has some good psychometric properties. Future research should address internal consistency and potential item redundancy, determine inter-rater reliability and change sensitivity.
\end{abstract}

\section{Keywords}

assessment; mental health; SRV; person-centred planning; personalisation; social inclusion; recovery

\section{Issue}

This article is part of the special issue "Indicators and Measurement of Social Inclusion", edited by Professor Peter Huxley (Bangor University, UK).

(C) 2015 by the authors; licensee Cogitatio (Lisbon, Portugal). This article is licensed under a Creative Commons Attribution 4.0 International License (CC BY).

\section{Introduction}

The SNQ measures the degree of support required by people with severe and enduring mental health conditions to achieve a socially inclusive lifestyle. It shares many underlying concepts with contemporary comprehensive social inclusion measures such as the Social and Community Opportunities Profile (SCOPE: Huxley et al., 2012).
The SNQ also attempts to measure the support people need to ameliorate damage to their identity caused by prolonged exposure to social devaluation (Kristiansen, 1998), stigma, discrimination and prejudice (Thornicroft, 2006; Wilkinson \& Marmot, 2003) and the negative practical, financial and social consequences that impede recovery (Allen, Balfour, Bell, \& Marmot, 2014; Levitas et al., 2007).

The multidimensional context of damaged social 
identity is increasingly recognised as significantly reducing service users' potential for personal recovery (Andresen, Oades, \& Caputi, 2003, 2006, 2011; Glover, 2012; Le Boutillier et al., 2011) and clinical recovery, which are now understood to be mutually reinforcing (Davidson \& Tondora, 2006; Glover, 2012; Slade, 2009). Multidimensional disadvantage is the sine qua non of deep exclusion (Levitas et al., 2007; Miliband, 2006).

The SNQ was designed to lead to balanced individual service plans that address the above issues by promoting personal and clinical recovery in the broadest terms.

This paper places the SNQ in context and describes its design rationale derived from Social Role Valorisation theory (SRV: Wolfensberger, 1983). The procedure for investigating aspects of the SNQ's reliability and validity is outlined and the results presented and discussed with reference to its performance against established psychometric criteria and conceptually related instruments. Utility, study limitations and future research requirements are noted.

\subsection{Background}

There is a long running debate in the literature on mental health assessment about how need should be conceptualised particularly in relation to social inclusion. The debate encompasses the domains of need that should be assessed, from which stakeholder perspective they should be chosen and the relative merits of objective and subjective judgements.

The recognition of the significance of social inclusion and exclusion for recovery has prompted intensified development and testing of a diverse set of social inclusion measures, their design informed by this debate. From early beginnings, where one or more social inclusion domains might be included in a primarily clinical instrument, new single issue inclusion-focussed scales have extended to wider concept coverage and the development of comprehensive inclusion measures. An ever growing set of design criteria have also emerged. A brief commentary follows to place the SNQ in its design context.

An early review by Lelliott (2000) highlighted the bias within the field towards developing solely service provider oriented assessment measures. Criteria for evaluating assessments to meet service user and professional requirements were proposed. Lelliott argued that instruments should go beyond clinical concerns and be comprehensive to cover the socially inclusive domains of work, employment, financial security, valued accommodation, choice and control over living circumstances, and maintaining relationships.

It was hoped this domain combination would lead to "balanced" service interventions to ameliorate clinical problems and reduce the broad impact of social exclusion.

The range of design criteria mentioned at that time, in addition to reliability and validity, included simplici- ty, being quick to learn and use in "real world" practice, meaningful individual and aggregate data and change sensitivity. Other criteria have emerged since. Particularly relevant to the present study are an explicit theoretical base, multi-layered and multidimensional unmet need focus, low cost, easy interpretation, completion by service users and staff in partnership, subjective and objective measures and a wide range of uses (Coombs, Nicholas, \& Pirkis, 2013; Davenport, 2006; Hampson, Killaspy, Mynors-Wallis, \& Meier, 2011; Huxley et al., 2012; Levitas et al., 2007).

Lelliott mentions the Camberwell Assessment of Need (CAN: Phelan et al., 1995) and the Avon Mental Health Measure (AMHM: LeGrand, 1996), now in its second iteration as "My View" (Health Care Improvement Scotland, 2011) as good examples.

The CAN establishes need in 22 domains. Accommodation, self-care, physical health, psychotic symptoms, daytime activities, relationships, education and benefits are relevant here. It assesses support services availability, met and unmet needs, appropriateness of support level and user satisfaction. It has service user and staff versions and good psychometric properties but agreement between staff and service user ratings is often low (Slade, Phelan, Thornicroft, \& Parkman, 1996).

The AMHM, designed by service users and professionals encourages partnership between service users and staff by articulating needs from the service user perspective. It includes a social integration/community participation scale, physical health, behaviour, access and mental health domains.

By 2006 Davenport observed a shift away from focussing solely on clinical needs towards identifying need for services and social supports. She mentions the promotion of social inclusion and recovery in NICE guidelines as new drivers of domain choice and suggested clinicians and service users collaborate on assessment.

Davenport mentions the CAN and also the Carers and Users Expectations of Services (CUES: Royal College of Psychiatrists et al., 2002) as containing socially inclusive domains. Relevant here are the CUES' domains of life and service choices, consultation and control, stigma and discrimination.

Recently Huxley et al. (2012) reviewed this field specifically for social inclusion measures whilst validating the SCOPE. Huxley's group has developed the SCOPE over many years. It is one of the most accepted and comprehensive measures of social inclusion (Coombs et al., 2013). It comprises a comprehensive domain set, derived from concept mapping of many stakeholder perspectives, subjective, objective and quality of life measures. It has good psychometric properties and is useable by the general population and mental health service users.

In their review, Huxley and colleagues identified two measures theoretically close to the SNQ. They also cite an early, conceptually identical version of the SNQ 
itself (Davis \& Lindley, 1999).

The Social Inclusion Scale (SIS: Hacking, Secker, Spandler, Kent, \& Shenton, 2008) was designed to measure social acceptance, social isolation and social relations outcomes in Arts and Mental Health projects. The SIS has objective and subjective elements, is concise, quick and easy to complete. It has been validated with mental health service users and students. It has some good psychometric properties and continues to be developed (Wilson \& Secker, in press).

The Inclusion Web (Bates, 2005) identifies the number and spread of valued relationships service users have and their use of mainstream community places in the domains of employment, education, volunteering, arts and culture, faith and meaning, family and neighbourhood, sports and exercise, and in services. The Inclusion Web essentially explores community participation and community presence. It is quick and easy to complete by service users and a support worker and leads to person-centred planning. The Inclusion Web has some good psychometric properties and is change sensitive (Hacking \& Bates, 2008).

Huxley and colleagues (2012) noted that all the SNQ's domains emerged in the concept mapping they conducted to validate the SCOPE. They state, "It is not clear how Davis and Lindley arrived at the domains or the statements (of the SNQ). However obtained, the concept mapping exercise provides some post hoc validation for the choice of domains or vice-versa!" ( $p$. 106). This paper's next section describes the SNQ's design rationale and, it is hoped, answers the question implied above.

\subsection{Design Rationale}

The SNQ was developed over many years clinical practice during which time we too recognised the need for "balanced" assessments (Lelliott, 2000). Our experience also led us to add a third layer to assessment and goal planning requiring social inclusion assessments to promote service plans actively seeking the amelioration of unacknowledged damage to social identity resulting from leading a socially devalued lifestyle (Kristiansen, 1998). Our approach is in line with professional commentaries (e.g. Huxley, 2001; Huxley et al., 2007) and services users' calls (e.g. Turner-Crowson \& Wallcraft, 2002) for services to address the social and psychological consequences of deep exclusion (Miliband, 2006), and extends this to measuring the support required to meet these needs.

In Learning Disabilities, SRV theory has guided services in addressing these issues for over thirty years. Focussing on person-centred planning, SRV targets services and culturally valued social supports to address service users' needs using inclusive (Department of Health [DOH], 2010) and personalised means (Think Local Act Personal, 2015). This approach is now being implemented in mental health services.

SRV has been cited as having informed many successful service delivery practices that support people to obtain, grow into and get rooted in valued social roles (Tyree, Kendrick, \& Block, 2011)-the cornerstones of inclusive practice. The SNQ's conceptual spine is based on John O'Brien's (1987) interpretation of SRV, the Five Service Accomplishments. These frame the goal domains of person-centred planning.

SRV proposes several perspectives and practices to address these issues. Three sets of need are identified. Kristiansen (1998) describes the first two as "universal basic needs" everyone has, for access to sustenance, shelter and affiliation, and "unique individual needs" that some people have arising from a specific condition such as an illness. SRV proposes a third kind of need that often goes unrecognised, for "revalorisation", or the restoration of damaged personal and social identity. Clinical experience tells us acknowledging this is the beginning of addressing deep exclusion and was central to the SNQ's design.

Multi-layered unmet need (Huxley \& Thornicroft, 2003; Levitas, 2006; Morgan, Burns, Fitzpatrick, Pinfold, \& Priebe, 2007) is fundamental to descriptions of social exclusion (Levitas et al., 2007) whilst addressing these multi-level unmet needs is central to promoting social inclusion (Cabinet Office-Social Exclusion Task Force, 2007). Addressing multi-level unmet need is important to successful "personalisation" (Bola, Coldham, \& Robinson, 2014) and indicative of progressive service cultures (Walker, Perkins, \& Repper, 2014). The "revalorisation" of identity is recognised as a recovery dimension and is found in recent conceptual frameworks for understanding clinical and personal recovery, although the language used differs (Andressen et al., 2003, 2006, 2011; Slade et al., 2011).

We designed an SRV derived assessment instrument to address multi-level need whilst accommodating commentators' recommendations for evaluating real world performance. Our aim was to conjoin the assessment of personal and clinical recovery needs with "revalorisation" needs, to facilitate individual service plans that address personal development and clinical change concurrently.

\subsection{Research Aims}

The following study describes the initial development and basic psychometric properties of the SNQ, including test-retest reliability, internal construct validity, concurrent validity and utility.

\section{Method}

\subsection{Participants}

Participants were five female and two male care co- 
ordinators in the rehabilitation and recovery service (DOH, 2002) of a Community Mental Health Team (CMHT), including two $\mathrm{G}$ and one F-Grade Nurses, one Senior Occupational Therapist, one Care Manager, one Senior Care Manager and one Clinical Psychologist. Most had considerable post-qualification SRV informed experience including using earlier versions of the SNQ ( $M=4.3$ yrs; range $1-8)$.

Care co-ordinators had to have known service users for six months, meeting weekly. Raters conducted SNQ ratings for service users for whom they were the sole care co-ordinator. Different raters therefore rated different service users. To standardise the SNQ, care coordinators rated the needs of eighty-two CMHT service users.

Ethical approval was obtained from a Local NHS Research Ethics Committee.

\subsection{Design}

A within subjects repeated measures design was used to determine test-retest reliability.

The Global Assessment Scale (GAS: Endicot, Spitzer, Fleiss, \& Cohen, 1976) and the MARC-2 (Huxley et al., 2000) were used to establish concurrent validity as they were being introduced into the local service system at the time of this study to evaluate a service reconfiguration. The MARC-2 was used to record demographic data.

\subsection{Setting}

The study was conducted in a predominantly white middle-class suburb with pockets of severe social deprivation.

The evolving SNQ was central to the team's clinical approach as part of a "Getting to Know You" process (Brost, Johnson, Wagner, \& Deprey, 1982) that led to Lifestyle Planning (O'Brien, 1987). The CMHT's service model provided health and social care to reduce personal distress and enhance social inclusion.

\subsection{Questionnaire Development}

The SNQ's item pool originated from staffs' unstructured clinical checklists, item choice being influenced by SRV thinking. The SNQ's present item set results from gradually restructuring these checklists into six SRV construct based item sets and two empirically derived item sets then regularly reviewing items for their perceived value to staff and service users.

Team members were clinically experienced having worked in resettlement, rehabilitation, residential care, assertive outreach and employment oriented services ( $n>50$ yrs). Many service users $(n>150)$ views were incorporated over ten years. Item pool revisions were agreed annually to continually enhance face validity.

The SNQ's item pool was further refined for the present study. 160 items were retained for their perceived clinical value and fit within the construct boundaries suggested by SRV.

We recognise prioritising comprehensiveness in the item pool would lead to statistical redundancy in the item set. From a pure design perspective this is undesirable but in this instance it was viewed as a requirement to maintain care standards and fulfil the design rationale. Formalisation of the SNQ was designed to bring rigour to identifying individual need and allow data aggregation to produce a population support needs profile, whilst maintaining an established and valued clinical tool.

\subsection{Materials}

The SNQ comprises eight discreet sub-scales (each printed with its own title, italicised below). Sub-scales contain 18-21 items. The total item set is 160 . The first five sub-scales follow O'Brien's Five Service Accomplishments with the sixth concept determined by the authors. The sub-scales are Community Presence (Living in their community), Community Participation (Getting involved in their community), Choice and Control (Making their own decisions), Social Roles and Respect (Being respected), Competence and Skills (Building on my client's strengths) and Finance (Money matters). Two further sub-scales include clinical problem items assessing Physical Health (Being fit and healthy) and Mental Health (My client's peace of mind).

The first six sub-scales measure support for "universal basic needs". The final two measure "unique individual needs". All sub-scales contain "revalorisation" items.

The first six sub-scales use seven-point scales ranging from "No Help" to "A Great Deal of Help". The final two sub-scales measure frequency on a seven-point scale from "Never" to "Always" allowing for "Never" to record no problem.

Each sub-scale contains a "criterion" question as the final item. This global sub-scale construct rating can be correlated with the remaining sub-scale items to obtain an internal validity measure. The full scale or SNQ total score aggregates the eight sub-scale scores indicating an overall level of support need.

The GAS, a global measure of psychiatric disability, was used as one measure of concurrent validity. The GAS is simple, has predictive power (Phelan, Wykes, \& Goldman, 1994) and has been used in similar research (e.g. Phelan et al., 1995). The MARC-2 collected demographics, service use data, and comparable service user problem ratings. The MARC- 2 has been used extensively in similar research (Huxley, 1997; Huxley, Reilly, \& Robinshaw, 1999). As a further measure of concurrent validity, a priori comparisons were agreed between specific MARC-2 categorical problem ratings and conceptually similar SNQ sub-scales (Table 1). Scores were then compared. 
Table 1. Conceptual relationship map between categorical MARC-2 problem severity ratings and SNQ subscales.

\begin{tabular}{ll}
\hline $\begin{array}{l}\text { MARC-2 problem } \\
\text { severity rating }\end{array}$ & SNQ sub-scale/s \\
\hline Relationship problems & $\begin{array}{l}\text { Community Participation } \\
\text { Social Roles \& Respect } \\
\text { Social Roles \& Respect } \\
\text { Competence \& Skills }\end{array}$ \\
Homemaking & $\begin{array}{l}\text { Competence \& Skills } \\
\text { Self-neglect }\end{array}$ \\
Personal care & $\begin{array}{l}\text { Physical Health } \\
\text { Finances }\end{array}$ \\
\hline
\end{tabular}

\subsection{Procedure}

To obtain consensus about the wording, meaning and sub-scale item location, team members including the study raters, attended two 1.5 hour workshops with the principal author and an independent service user consultant to conduct a detailed analysis of sub-scale items. Consensus on the rating scales' wording was also achieved.

The SNQ was then re-checked for face, content and consensual validities amongst current staff and service users by the independent service user consultant who also reviewed the wording to be more ordinary by accommodating low reading age and attending to good grammar and lack of ambiguity.

GAS and MARC- 2 training was provided to raters by independent researchers from Durham University. Training was provided in using the GAS because of its reported variable reliability ( $r=0.62$ to 0.91 ) (Dworkin et al., 1990). The inter-rater reliability of the MARC-2 is $87 \%$. Its internal reliability using Cronbach's " $\alpha$ " is 0.83 (Huxley et al., 2000).

SNQ test-retest reliability was determined by rating service users' needs with the SNQ twice $\left(T_{1} \& T_{2}\right)$ at a two/three week interval without conferring. Raters completed GAS and MARC-2s in the same week as, but after the second SNQ rating. GAS ratings recorded service users' lowest functioning during the preceding month.

\section{Results}

\subsection{Sample}

The study sample's characteristics are shown in Table 2. The continuously distributed data including age, length of illness, GAS and relevant MARC-2 scores' distributions were inspected visually and were normal.

The population were predominantly male with an ethnic distribution typical of outer London. Mean age was 47.82 years. A mean of 20.94 years of service use and a mean of 1.35 admissions in the preceding two years suggested a population with long term problems. A mean GAS score of 38.91 and past formal Mental Health Act status in $63.4 \%$ suggested a severely disabled population. The main diagnosis was schizophrenia (70.72\%). Most were single (65.1\%), lived alone (38.6\%) or with non-family $(30.1 \%)$ in their own homes $(67.8 \%)$.

The study population was demographically similar to those in comparable research (Phelan, Wykes, \& Goldman, 1994; Phelan et al., 1995). Fifty percent were within the GAS range of having "serious symptomatology" and being "unable to function in most areas". Compared with large-scale studies ( $n=3000$; Huxley et al., 1999) the present study population was severely disabled and likely to experience unmet need.

There were no significant associations between SNQ full-scale totals and diagnosis, gender, onset age, ethnicity, marital status, previous two years admissions, past Mental Health Act status or who people lived with. There were statistically significant correlations between higher levels of overall support needs for inclusion and health (SNQ totals) and increasing age ( $r=0.28, p=0.013)$, years ill $(r=0.40, p<0.001)$ and years using services $(r=0.42, p<0.001)$. These relationships might be expected clinically as the older members of the study population had spent many years living in long-stay hospitals.

Given the small sample size in this study it is not possible to be specific about gender or race effects on support needs.

\subsection{Rater Independence}

Small numbers of raters, each scoring different service users, can cause restricted variance in scores. Therefore it was important to establish whether SNQ scores resulted from a similar rating style across raters or genuine differences in service user characteristics. Otherwise it could be argued the psychometric tests applied are simply measuring the extent to which raters have a similar rating style.

To account for this, scatter plots of the distribution patterns of each rater's scores on each sub-scale, the SNQ total score and the GAS were compared. These patterns were inspected visually and compared across raters and against the combined raters' distribution of scores on the same measures. Visual inspection revealed no discernible shared distribution patterns, central tendency or other distribution features. Individual rater's patterns did not match each other's distribution patterns or the raters' collective distribution pattern. Numerical means, standard deviations and ranges were also visually examined producing the same results. The remaining psychometric tests were performed assuming ratings were likely to be independent and any properties found would result from the SNQ's capacity to measure service user characteristics not rating style. 
Table 2. SNQ reference population demographics.

\begin{tabular}{|c|c|c|c|}
\hline Factor & Mean & SD & Range \\
\hline Age & 47.82 & 13.65 & $24-76$ \\
\hline Onset age & 26.11 & 10.15 & $8-55$ \\
\hline Years ill & 21.86 & 13.78 & $1-51$ \\
\hline Years using services & 20.94 & 13.93 & $2-51$ \\
\hline Last $2 y r s$ admissions & 1.35 & 2.12 & $0-12$ \\
\hline GAS & 38.91 & 13.56 & $11-81$ \\
\hline Gender & 53 Men (64.6\%) & 29 Women (35.4\%) & \\
\hline \multirow[t]{2}{*}{ MHA status } & 52 Yes (63.4\%) & 30 No $(36.6 \%)$ & \\
\hline & Category & Frequency & $\%$ \\
\hline \multirow[t]{4}{*}{ Ethnicity } & White British & 70 & 80.0 \\
\hline & Afro-Caribbean & 2 & 2.3 \\
\hline & British Asian & 2 & 2.3 \\
\hline & Other/Don't Know & 8 & 8.8 \\
\hline \multirow[t]{6}{*}{ Diagnosis } & Schizophrenia & 57 & 70.72 \\
\hline & Paranoid Psychosis & 2 & 2.44 \\
\hline & Manic Depression & 8 & 9.76 \\
\hline & Psychotic Depression & 3 & 3.66 \\
\hline & Anxiety/Depression & 4 & 4.88 \\
\hline & Other & 8 & 8.54 \\
\hline \multirow[t]{5}{*}{ Status } & Single & 53 & 65.1 \\
\hline & Divorced & 15 & 18.1 \\
\hline & Separated & 3 & 3.6 \\
\hline & Married & 6 & 7.2 \\
\hline & Widowed & 5 & 6.0 \\
\hline \multirow[t]{7}{*}{ Living situation } & Alone & 31 & 38.6 \\
\hline & Parents & 11 & 13.3 \\
\hline & Spouse/partner & 5 & 6.0 \\
\hline & Spouse/children & 3 & 3.6 \\
\hline & Children/single parent & 1 & 1.2 \\
\hline & Other family & 6 & 7.2 \\
\hline & Non-family & 25 & 30.1 \\
\hline \multirow[t]{6}{*}{ Accommodation } & Homeless & 2 & 2.4 \\
\hline & Own home (unsupported) & 25 & 32.1 \\
\hline & Own home (supported) & 30 & 35.7 \\
\hline & Shared home & 3 & 3.6 \\
\hline & Residential home & 16 & 19.0 \\
\hline & Nursing home & 6 & 7.1 \\
\hline
\end{tabular}

\subsection{Exploratory Analysis}

Up to five missing items per sub-scale were replaceable with the same sub-scale mean. The total number of missing items at $T_{1}$ was $91\left(T_{2}=94\right)$ from a total 13,120 data points $(<1 \%)$. The SNQ full-scale total, all SNQ subscale totals and GAS scores were normally distributed, with non-significant results on the Kolmogorov-Smirnov goodness of fit test (Stephens, 1974) and visual inspection of box and whisker plots and histograms, thus allowing the use of parametric tests. There was slight positive skewing only on Community Presence, which when transformed with the formula $\log _{10}(1+$ variable) produced a normal curve, using the above methods. Outliers were meaningful and included. Kurtosis appeared minimal using the above methods. No further formal testing was conducted.

Descriptive (pre-transformation for Community
Presence) statistics for SNQ full-scale total and subscale totals at $T_{1}$, and the GAS are shown in Table 3. MARC-2 categorical problem severity levels were comparable with previous research (Huxley et al., 1999) with similar populations (see Table 7).

\subsection{Internal Construct Validity}

Two-tailed Pearson's " $r$ " correlations between the SNQ sub-scale totals excluding the sub-scale criterion question score and the sub-scale criterion question score itself were all significant $(p<0.001)(n=82)$ (Table 4). This result may present a way forwards for a short version of the SNQ. The criterion questions could be a potential source of items although such an instrument would have a very different purpose to that of the clinically comprehensive full version. 
Table 3. Descriptive statistics for SNQ total, sub-scale scores and GAS ratings at $T_{1}$.

\begin{tabular}{lrrrrrr}
\hline Scale (combined) & Full scale & Mean & SD & Range & Items & $\boldsymbol{n}$ \\
\hline SNQ total (sub-scales 1-8) & 1120 & 573.00 & 159.92 & $244-964$ & 160 & 82 \\
1. Community Presence & 140 & 59.14 & 29.98 & $23-137$ & 20 & 82 \\
2. Community Participation & 140 & 90.44 & 30.83 & $30-140$ & 20 & 82 \\
3. Choice \& Control & 126 & 66.97 & 25.74 & $22-124$ & 18 & 82 \\
4. Social Roles \& Respect & 133 & 73.50 & 22.65 & $25-123$ & 19 & 82 \\
5. Competence \& Skills & 147 & 77.02 & 26.15 & $27-143$ & 21 & 82 \\
6. Finance & 140 & 72.80 & 31.54 & $20-136$ & 20 & 82 \\
7. Physical Health & 147 & 60.85 & 20.61 & $21-117$ & 21 & 82 \\
8. Mental Health & 147 & 72.26 & 16.41 & $36-116$ & 21 & 82 \\
GAS & 100 & 38.91 & 13.56 & $11-81$ & $(10)$ & 82 \\
\hline
\end{tabular}

Table 4. Internal construct validity and test-retest reliability for SNQ sub-scales and SNQ total.

\begin{tabular}{|c|c|c|c|c|}
\hline SNQ sub-scales at $T_{1}$ (sub-scales 1-8) & $n$ & Pearson's "r" & Pearson's "r" (2-tailed) & Sub-scale Items \\
\hline & & Internal Validity & Test-retest Reliability & $N$ \\
\hline 1. Community Presence & 73 & $0.83^{*}$ & $0.91^{*}$ & 20 \\
\hline 2. Community Participation & 72 & $0.84 *$ & $0.87 *$ & 20 \\
\hline 3. Choice \& Control & 77 & $0.82 *$ & $0.89 *$ & 18 \\
\hline 4. Social Roles \& Respect & 75 & $0.82 *$ & $0.90 *$ & 19 \\
\hline 5. Competence \& Skills & 73 & $0.52 *$ & $0.92 *$ & 21 \\
\hline 6. Finance & 74 & $0.86^{*}$ & $0.93 *$ & 20 \\
\hline 7. Physical Health & 72 & $0.52 *$ & $0.88^{*}$ & 21 \\
\hline 8. Mental Health & 76 & $0.48^{*}$ & $0.88^{*}$ & 21 \\
\hline SNQ total (1-8 combined) & & & $0.92 *$ & 160 \\
\hline SNQ (1-6 combined) & & & $0.93 *$ & 118 \\
\hline SNQ (7-8 combined) & & & $0.89 *$ & 42 \\
\hline
\end{tabular}

\subsection{Test-retest Reliability}

Two-tailed Pearson's " $r$ " product moment correlations between $T_{1}$ and $T_{2}$ were all significant at $p<0.001(n=$ 82). Correlational test-retest reliability of the SNQ fullscale total was 0.92. Because different measurement scales are used in the first six and last two sub-scales their reliability and validity were calculated separately (Table 4). Correlational test-retest reliability for the first six sub-scales combined was 0.93 , and the last two combined 0.89. The correlation between the SNQ full-scale total at $\mathrm{T}_{1}$ and the first six sub-scales was 0.98 , and 0.64 with the last two.

To determine any consistent mean score drift across raters, a two-tailed t-test was computed for each subscale, the combined first six and last two sub-scales (for the same reasons given above) and the SNQ full-scale total (Table 5). The first three sub-scales showed no significant drift. The remaining five sub-scales, the first six and last two sub-scales combined and the SNQ full-scale total showed small statistically significant downwards drift between $T_{1}$ and $T_{2}$.

\subsection{Concurrent Validity}

$T_{1}$ and $T_{2}$ SNQ full-scale totals, combined first six and combined last two sub-scale totals, and individual subscale total scores were significantly negatively (because they are calibrated in opposite directions) correlated with the GAS ( $n=82$ ) (Table 6).

Concurrent validity was explored further by comparing a priori determined conceptually related MARC-2 three-point categorical problem severity ratings (see Table 1) and $T_{1}$ SNQ total scores.

One-way ANOVAs (two-tailed) followed by Scheffé multiple range tests (Salkind, 2010) were used to distinguish significant differences between ratings on the categorical scales of the MARC-2.

SNQ total scores for people with severe problems (and moderate problems for personal care rated on the MARC-2) were significantly greater than scores for people with moderate and/or no problems in all domains except relationship problems (Table 7, upper section).

Conceptually related MARC- 2 problem severity ratings and SNQ sub-scale scores were compared. One-way ANOVAs (two-tailed) followed by Scheffé multiple range tests were conducted to distinguish significant differences between categories.

In all instances people with severe problems (on MARC-2 categorical scores) had significantly higher support needs (SNQ sub-scale scores) than people rated with no problems on the MARC-2. In some instances people with severe problems also had significantly higher support needs than people with moderate problems. For others, people with moderate problems had significantly higher support needs than people without problems (Table 7, lower section). 
Table 5. Test-retest reliability drift for SNQ total and sub-scales.

\begin{tabular}{|c|c|c|c|c|c|c|c|c|c|}
\hline SNQ total \& sub-scales & Mean $T_{1}$ & Mean $T_{2}$ & Mean Diff & SD & "t" (2-tail) & Df & $\boldsymbol{P}$ & $\mathbf{n}$ & Full Scale \\
\hline 1. Community Presence & 59.15 & 57.82 & 1.33 & 13.31 & 0.91 & 81 & 0.367 & 20 & 14 \\
\hline 2. Community Participation & 90.44 & 88.15 & 2.29 & 15.68 & 1.32 & 81 & 0.190 & 20 & 14 \\
\hline 3. Choice \& Control & 66.97 & 65.25 & 1.71 & 11.53 & 1.34 & 81 & 0.183 & 18 & 12 \\
\hline 4. Social Roles \& Respect & 73.50 & 70.70 & 2.80 & 9.70 & 2.61 & 81 & $0.011^{*}$ & 19 & \\
\hline 5. Competence \& Skills & 77.02 & 73.65 & 3.36 & 10.50 & 2.90 & 81 & $0.005^{*}$ & 21 & 14 \\
\hline 6. Finance & 72.80 & 69.22 & 3.59 & 12.01 & 2.70 & 81 & $0.008 *$ & 20 & 14 \\
\hline 7. Physical Health & 60.86 & 58.22 & 2.63 & 10.16 & 2.35 & 81 & $0.021 *$ & 21 & \\
\hline 8. Mental Health & 72.26 & 69.59 & 2.67 & 8.45 & 2.86 & 81 & $0.005^{*}$ & 21 & \\
\hline SNQ total ( $1-8$ combined) & 573.00 & 552.62 & 20.39 & 61.78 & 2.99 & 81 & $0.004 *$ & 160 & 112 \\
\hline SNQ (1-6 combined) & 439.89 & 424.81 & 15.08 & 54.07 & 2.53 & 81 & $0.014 *$ & 118 & \\
\hline SNQ (7-8 combined) & 133.86 & 127.81 & 6.05 & 15.48 & 3.54 & 81 & $0.001 *$ & 42 & \\
\hline
\end{tabular}

Note: ${ }^{*} p<0.05(n=82)$.

Table 6. Concurrent validity of SNQ total and sub-scales with GAS using Pearson's " $r$ ".

\begin{tabular}{|c|c|c|c|c|}
\hline Scale & GAS vs $T_{1}(r)$ & $p\left(\mathrm{~T}_{1}\right)$ & GAS vs $T_{2}(r)$ & $p\left(\mathrm{~T}_{2}\right)$ \\
\hline SNQ total (1-8 combined) & -0.57 & $<0.001$ & -0.54 & $<0.001$ \\
\hline SNQ (1-6 combined) & -0.56 & $<0.001$ & -0.53 & $<0.001$ \\
\hline SNQ (7-8 combined) & -0.34 & 0.002 & -0.38 & 0.001 \\
\hline 1. Community Presence & -0.48 & $<0.001$ & -0.46 & $<0.001$ \\
\hline 2. Community Participation & -0.54 & $<0.001$ & -0.47 & $<0.001$ \\
\hline 3. Choice \& Control & -0.45 & $<0.001$ & -0.75 & $<0.001$ \\
\hline 4. Social Roles \& Respect & -0.52 & $<0.001$ & -0.65 & $<0.001$ \\
\hline 5. Competence \& Skills & -0.54 & $<0.001$ & -0.49 & $<0.001$ \\
\hline 6. Finance & -0.37 & 0.001 & -0.36 & 0.001 \\
\hline 7. Physical Health & -0.38 & $<0.001$ & -0.39 & $<0.001$ \\
\hline 8. Mental Health & -0.24 & 0.03 & -0.26 & 0.017 \\
\hline
\end{tabular}

Table 7. MARC-2 problem severity rating scores versus SNQ full-scale total and sub-scale scores.

\begin{tabular}{|c|c|c|c|c|c|c|}
\hline $\begin{array}{l}\text { MARC-2 versus SNQ full-scale total (sub- } \\
\text { scales 1-8) }\end{array}$ & “F” & $\boldsymbol{P}$ & d.f. & $\begin{array}{l}\text { SNQ Mean } \\
\text { for "None" }\end{array}$ & $\begin{array}{l}\text { SNQ Mean for SNQ I } \\
\text { "Moderate" }\end{array}$ & $\begin{array}{l}\text { Mean for } \\
\text { "Severe" }\end{array}$ \\
\hline Relationships & 2.3456 & 0.1027 & 2,76 & 435 & 526 & 526 \\
\hline Homemaking & 18.0290 & $<0.0001$ & 2,77 & 411 & 481 & $608 * *$ \\
\hline Occupation & 7.3542 & 0.0012 & 2,77 & 412 & 476 & $559 * *$ \\
\hline Self-Neglect & 3.6510 & 0.0307 & 2,75 & 498 & 538 & $659 *$ \\
\hline Personal Care & 14.0487 & $<0.0001$ & 2,77 & 428 & $532 *$ & $608^{*}$ \\
\hline Finances & 3.1928 & 0.0465 & 2,77 & 483 & 517 & $606^{*}$ \\
\hline \multicolumn{7}{|l|}{ MARC-2 vs SNQ sub-scales } \\
\hline Relationships vs Community Participation & 4.5147 & 0.0140 & 2,76 & 72 & 87 & $101^{*}$ \\
\hline Relationships vs Social Roles \& Respect & 5.3923 & 0.0065 & 2,76 & 57 & 72 & $81^{*}$ \\
\hline Homemaking vs Competence \& Skills & 22.8528 & $<0.0001$ & 2,77 & 57 & 69 & $97^{* *}$ \\
\hline Daily Occupation vs Social Roles \& Respect & 6.0866 & 0.0035 & 2,77 & 58 & 67 & $80 * *$ \\
\hline Daily Occupation vs Competence \& Skills & 6.7116 & 0.0021 & 2,77 & 62 & 68 & $86^{* *}$ \\
\hline Self-Neglect vs Physical Health & 3.5200 & 0.0346 & 2,75 & 59 & 64 & $83^{*}$ \\
\hline Personal Care vs Physical Health & 12.4880 & $<0.0001$ & 2,77 & 48 & $63^{*}$ & $75^{*}$ \\
\hline Financial vs Finances & 3.5900 & 0.0323 & 2,77 & 66 & 72 & $96 *$ \\
\hline
\end{tabular}

Note: * significantly higher SNQ score compared to MARC-2 "none" score; ${ }^{* *}$ significantly higher SNQ score compared to MARC-2 "moderate"; "none" scores.

\subsection{Utility}

To explore the SNQ's utility the principal researcher and the independent service user consultant directly observed raters' behaviour and obtained their verbal self-reports.

Raters said they were familiar with the SNQ and used it before service users' Lifestyle Planning reviews. They liked the format and the separation of scales into distinct constructs. They said the questions were highly relevant to their clinical practice. They showed interest in knowing how their ratings might compare with service users' and families' ratings.

Raters were concerned at completing all the subscales in one sitting without service user input. The research methodology was at odds with their usual practice of completing sub-scales singly with service users. 
They said their approach would be better for individual person-centred planning as they routinely used the SNQ as a structured interview not a "test".

Raters took fifteen-twenty minutes to complete the SNQ reporting that it took longer in practice to fully involve service users in single sub-scale "discussions".

\section{Discussion}

\subsection{Study Limitations}

The main methodological challenge of the present study was the necessity to investigate a clinical assessment instrument in vivo. Service users' needs were rated by a small number of staff who knew them well enough to do so accurately. Each rater rated different service users. This did not allow for the measurement of inter-rater reliability which is a limitation.

Given these constraints the authors consider the present method a sufficient test of the above issues. A more ideal scenario would involve many raters rating the same service users. This might be possible in an Assertive Outreach Team because all service users should be well known to all team members (Cupitt, 2013).

Our use of the GAS should be noted. The GAS was developed in the late 1970s and has been superseded by the modified Global Assessment of Functioning (GAF: Hall, 1995). The GAF has modified criteria, better instructions and psychometric properties (Aas, 2011) designed to reduce biasing caused to the GAS's other aspects by its inclusion of symptomatology ratings. The GAF would have been better used in this study. However the service was using the GAS for other purposes and it was not possible to introduce an additional alternative assessment to validate the SNQ. We did however provide training to compensate for the GAS's reported low reliability. The GAF would be preferred over other GAS derivatives because they address the biasing issue by removing symptomatology ratings (e.g. the SOFAS: Morosini, Magliano, Brambilla, Ugolini, \& Pioli, 2000) but we required these to assess the construct validity of the SNQ's Mental Health sub-scale.

The SNQ requires further item analysis to check for redundancy, and assess, and if necessary, increase internal consistency through the "alpha if item deleted" method (Raykov, 2008). This approach can reduce redundancy by indicating those items that can be removed where their deletion increases internal consistency. However a careful balance needs to be struck between developing a psychometrically valid instrument and maintaining a comprehensive clinical tool that facilitates collaborative, rich, clinical conversations about need. Likewise if the validity of the sub-scale criterion questions could be established this might lead to a psychometrically robust short-form of the SNQ, but its use would be limited to providing aggregated data for service evaluation purposes.

\subsection{Which Needs Required What Levels of Support?}

Aggregate population sub-scale profiles identified Community Participation as the highest support need, the mean rating being between "a fair amount of help" and "a good deal of help". The least support need was for Community Presence, the mean rating being "a bit of help". This is congruent with hospital closure studies that found physical integration was more successful than social integration (Knapp et al., 1992; Leff, 1995). It was likely that this population was deeply excluded. This would be consistent with many of the study population having lived in hospital for long periods.

Physical Health support needs were second lowest having a mean rating of less than "a bit of help". This could represent unrecognised need, as is often reported (DOH, 2006), or may be because this $\mathrm{CMHT}$ made physical health a priority.

\subsection{Psychometric Evaluation and Implications for Future Research}

The exploratory analyses of the SNQ full-scale and subscales revealed some good scale properties. Sub-scales showed normal distributions. There was good spread and no floor or ceiling effects. The SNQ was well calibrated for its reference population. It should be suitable for use with populations having a wider disability range.

There was no drift over time in scores on the first three sub-scales. The remaining five and the SNQ fullscale total showed small statistically significant but clinically insignificant downward drift.

Test-retest reliability of the SNQ full-scale total and all sub-scale totals was high and significantly correlated. However it would be appropriate to investigate testretest reliability at the item level in future research.

In addition to item test-retest reliability, internal consistency analysis is required and is likely to show redundancy. Internal validity was good with the subscale criterion items showing possibilities for developing an SNQ short form if combined with an internal consistency analysis.

Concurrent validity for the SNQ full-scale total with the MARC-2 was good and comparable with an established needs assessment in mental health (Phelan et al., 1995) and good for the first five sub-scales. The Finance, Physical Health and Mental Health sub-scales had the lowest correlations with the SNQ full-scale total and only moderate concurrent validity with the GAS. Most sub-scales' internal validity was high. For Competence and Skills, Physical Health and Mental Health it was good.

No significant scale construction problems were identified in the first six sub-scales except relatively lower internal validity on Competence and Skills. The poorer internal validity for Physical and Mental Health may be due to using a frequency rating. However, it is 
more likely this results from the greater diversity of concepts used in their construction compared to the more focussed SRV derived sub-scales. This requires further investigation.

The moderate concurrent validity with the GAS for the Finance, Physical and Mental Health sub-scales may also be due to the above. The most likely explanation however would be the conceptual dissimilarity of the Finance and Physical Health sub-scales to those of the GAS. The high concurrent validity for the Physical Health and Finance sub-scales with MARC-2 problem severity ratings on personal care and self-neglect supports this. The low concurrent validity for the Mental Health sub-scale remains a concern.

Concurrent validity for the Community Participation, Social Roles and Respect, and Competence and Skills sub-scales was also high compared to the MARC-2's conceptually similar problem severity ratings of relationships, homemaking and daily occupation problems.

The SRV derived sub-scales were designed to measure support to meet 'universal basic needs'. The problem identification scales were designed to measure support for meeting 'unique individual needs'. It would be interesting to conduct a factor analytic study to investigate whether the SNQ's underlying conceptual structure suggests the above is a valid separation of 'kinds of need'.

\subsection{Utility}

Raters completed the full item set in reasonable time but found scoring all sub-scales at once at odds with routine clinical practice. They said it seemed artificial without service user involvement. Their usual practice involved working through each sub-scale on a separate occasion with full user participation. They reported the most helpful method in guiding individual service planning was rating different sub-scales on separate occasions.

\section{Conclusions}

Within the context of necessary methodological limitations this study has demonstrated that the SNQ can differentiate between service users' relatively low support needs to achieve community presence and high levels for community participation (Knapp et al., 1992; Leff, 1995). The SNQ has good reliability and validity in most domains, especially those derived from SRV. Subscales not derived from SRV were weaker. The low concurrent validity with the GAS for the Finance and Physical Health sub-scales could be expected but not for the Mental Health sub-scale. In the latter two subscales using frequency to measure support, rather than amount per se, may have confounded the results.

To address the limits of the present study further research is warranted, including an investigation of any differences to be found in care co-ordinator and service user/carer ratings (Slade et al., 1996; Slade, Thornicroft, Loftus, Phelan, \& Wykes, 1999), its internal consistency, inter-rater reliability; test-retest reliability at the individual item level and change sensitivity. Factor analysis and item reduction would be important for developing the SNQ as a research instrument, particularly as an outcome measure, although this would necessarily reduce its comprehensiveness as a clinical tool. Other areas for investigation should address respondent burden and obtain a more detailed subjective appreciation from staff, service users and carers.

\section{Acknowledgements}

This paper is dedicated to the memory of Richard K. Sutton, user involvement frontiersman, who acted as the independent service user consultant to the research and who sadly died before this paper could be submitted for publication.

\section{Conflict of Interests}

The authors declare no conflict of interests.

\section{References}

Aas, I. H. M. (2011). Guidelines for rating Global Assessment of Functioning (GAF). Annals of General Psychiatry, 10(2), 1-11.

Allen, J., Balfour, R., Bell, R., \& Marmot, M. (2014). Social determinants of mental health. Geneva, Switzerland: World Health Organization and Calouste Foundation.

Andresen, R., Oades, L. G., \& Caputi, P. (2003). The experience of recovery from schizophrenia: Towards an empirically validated stage model. Australia and New Zealand Journal of Psychiatry, 37, 586-594.

Andresen, R., Oades, L. G., \& Caputi, P. (2006). The Stages of Recovery Instrument: Development of a measure of recovery from serious mental illness. Australia and New Zealand Journal of Psychiatry, 40, 872-980.

Andresen, R., Oades, L. G., \& Caputi, P. (2011). Psychological recovery: Beyond mental illness. West Sussex, UK: Wiley Blackwell.

Bates, P. (2005). The Inclusion Web. Bath, UK: National Development Team for Inclusion.

Bola, M., Coldham, T., \& Robinson, Z. (2014). A study of personalisation and the factors affecting the uptake of personal budgets by mental health service users in the UK: A research study commissioned by MIND. Project Report. Preston, UK: Centre for Citizenship and Community, University of Central Lancashire. Retrieved from http://clok.uclan.ac.uk/10755

Brost, M., Johnson, T., Wagner, L., \& Deprey, R. (1994). Getting to know you: One approach to service as- 
sessment and planning for individuals with disabilities. Madison, US: Wisconsin Coalition for Advocacy (distributed in Britain by Values into Action).

Cabinet Office-Social Exclusion Task Force. (2007). Reaching out: Progress on social exclusion. London, UK: HM Government.

Coombs, T., Nicholas, A., \& Pirkis, J. (2013). A review of social inclusion measures. Australian and New Zealand Journal of Psychiatry, 47(10), 906-919.

Cupitt C. (2013). Clinical psychologists and assertive outreach. Leicester, UK: British Psychological Society.

Davenport, S. (2006). Ensuring the community cares: Assessment and evaluation of social care needs in long term mental illness. Advances in Psychiatric Treatment, 12, 45-53.

Davidson, L., \& Tondora, J. (2006). Practice guidelines for recovery-oriented behavioural health care. Yale, USA: Connecticut Department of Mental Health and Addiction Services, Yale University Program for Recovery and Community Health.

Davis, F. A., \& Lindley, P. (1999). The Support Needs Questionnaire. (Available from Fabian Davis, London, UK: Oxleas NHS Trust: 100255.3512@ compuserve.com.)

Department of Health. (2002). Mental health policy implementation guide: Community mental health teams. London, UK: HM Government.

Department of Health. (2006). Choosing health: Supporting the physical needs of people with severe mental illness. London, UK: DH/Mental Health.

Department of Health. (2010). Personalisation through person-centred planning. London, UK: HM Government.

Dworkin, R. J., Friedman, L. C., Felschow, R. I., Grant, K. D., Mottie, H. S., \& Scott, V. J. (1990). The longitudinal use of the Global Assessment Scale in multiplerater situations. Community Mental Health Journal, 26, 335-344.

Endicot, J., Spitzer, R. L., Fleiss, J. L., \& Cohen, J. (1976). The Global Assessment Scale. Archives of General Psychiatry, 33, 766-779.

Glover, H. (2012). Recovery, life-long learning, social inclusion and empowerment: Is a new paradigm emerging? In P. Ryan., S. Ramon., \& T. Greacen (Eds.), Empowerment, lifelong learning and recovery in mental health: Towards a new paradigm. London, UK: Palgrave MacMillan.

Hacking, S., \& Bates, P. (2008). The Inclusion Web as a tool for person-centred planning and service evaluation. Mental Health Review Journal: Research, Policy and Practice, 13, 4-15.

Hacking, S., Secker, J., Spandler, H., Kent, L., \& Shenton, J. (2008). Evaluating the impact of participatory art projects for people with mental health needs. Health \& Social Care in the Community, 16, 638-648.

Hall, R. C. (1995). Global assessment of functioning. A modified scale. Psychosomatics, 36(3), 267-275.
Hampson, M., Killaspy, H., Mynors-Wallis, L., \& Meier, R. (2011). Outcome measures recommended for use in adult psychiatry. (Op 78). London, UK: Royal College of Psychiatry.

Health Care Improvement Scotland. (2011). My View. Retrieved from http://www.healthcareimprovement scotland.org/our_work/mental_health/programme_ resources/my_view.aspx

Huxley, P. (1997). Describing mental health services: The development of a mental health census in the North West of England. In M. Tansella (Ed), Making rational mental health services. Rome, Italy: II Pensiero Scientifico Editore.

Huxley, P. (2001). The contribution of social science to mental health services research and development: A SWOT analysis. Journal of Mental Health, 10, $117-$ 120.

Huxley, P., \& Thornicroft, G. (2003). Social inclusion, social quality and mental illness. British Journal of Psychiatry, 182(4), 289-290.

Huxley, P., Evans, S., Madge, S., Webber, M., Burchardt, T., McDaid, D., \& Knapp, M. (2012). Development of a social inclusion index to capture subjective and objective life domains (phase II): Psychometric development study. Health Technology Assessment, 16(1), 3-255.

Huxley, P., Evans, S., Munroe, M., Webber, M., Burchardt, T., Knapp, M., \& McDaid, D. (2007). Social inclusion index project, $\mathrm{DOH}$ health technology assessment programme. Swansea, Wales: Centre for Social Care Work Research, University of Wales.

Huxley, P., Reilly, S., Gater, R., Robinshaw, E., Harrison, J., Mohamed, H., Butler, T., \& Windle, B. (2000). Matching resources to care, the acceptability, validity and inter-rater reliability of a new instrument to assess severe mental illness (MARC-1). Social Psychiatry \& Psychiatric Epidemiology, 35, 312-317.

Huxley, P., Reilly, S., \& Robinshaw, E. (1999). The care provided by health and social services for people with the characteristics of severe mental illness. Final report for the Department of Health. Manchester, UK: University of Manchester.

Knapp, M., Cambridge, P., Thomason, C., Beecham, J., Allen, C., \& Darton, R. (1992). Care in the community: Challenge and demonstration. Aldershot, UK: Ashgate.

Kristiansen, K. (1998). Needs and social role valorisation. UK SRV Newsletter, 3, 3-7. Retrieved from http://www.21century.com.au/jarm/srv/srvweb.html

Le Boutillier, C., Leamy, M., Bird, V.J., Davidson, L., Williams, J., \& Slade, M. (2011). What does recovery mean in practice? A qualitative analysis of international recovery-oriented practice guidance. Psychiatric Services, 62(12), 1470-1476.

Leff, J. (1995). Long stay patients seven years after discharge from hospital: Outcome. In Tenth Annual Conference of the Team for the Assessment of Psy- 
chiatric Services Summary of Proceedings. London, UK: TAPS

LeGrand, D. (1996). The Avon Mental Health Measure. Bristol, UK: Bristol Social Services and South West MIND.

Lelliott, P. (2000). What do people want from specialist mental health services and can this be measured in routine settings? Behavioural and Cognitive Psychotherapy, 28, 361-368.

Levitas, R. (2006). The concept and measurement of social exclusion. In D. Pantazis, D. Gordon, \& R. Levitas (Eds.), Poverty and social exclusion in Britain: The millennium survey (pp. 123-160). Bristol, UK: Policy Press.

Levitas, R., Pantazis, C., Fahmy, E., Gordon, D., Lloyd, E., \& Patsios, D. (2007). The multidimensional analysis of social exclusion. A research report for the Social Exclusion Task Force. Bristol, UK: Department of Sociology \& School for Social Policy, Townsend Centre for the International Study of Poverty and Bristol Institute for Public Affairs, University of Bristol.

Miliband, D. (2006). Social exclusion: The next steps forward. London, UK: ODPM.

Morgan, C., Burns, T., Fitzpatrick, J., Pinfold, V., \& Priebe, S. (2007). Social exclusion and mental health: Conceptual and methodological review. British Journal of Psychiatry, 191, 477-483.

Morosini, P. L., Magliano, L., Brambilla, L., Ugolini, S., \& Pioli, R. (2000). Development, reliability and acceptability of a new version of the DSM-IV Social and Occupational Functioning Assessment Scale (SOFAS) to assess routine social functioning. Acta Psychiatrica Scandinavica, 101, 323-329.

O'Brien, J. (1987). A guide to lifestyle planning. In B. Wilcox \& G. T. Bellamy (Eds.), A comprehensive guide to the activities catalogue. An alternative curriculum for youth and adults with severe disabilities (pp. 175-188). Baltimore, US: Paul H Brookes.

Phelan, M., Slade, M., Thornicroft, G., Dunn, G., Holloway, F., Wykes, T., Strathdee, G., Loftus, L., McCrone, P., \& Hayward, P. (1995). Camberwell Assessment of Need (CAN): The validity and reliability of an instrument to assess the needs of people with severe mental illness. British Journal of Psychiatry, 167, 589-595.

Phelan, M., Wykes, T., \& Goldman, H. (1994). Global Function Scales. Social Psychiatry, 29, 205-211.

Raykov, T. (2008). Alpha if deleted: A note on criterion validity loss in scale revision if maximising coefficient alpha. British Journal of Mathematical and Statistical Psychology, 61, 275-285.

Royal College of Psychiatrists, Royal College of Nursing
Research Institute, Rethink, et al. (2002). CUES: Carers' and Users' Expectations of Services. Service User Questionnaire. London, UK: Rethink. Retrieved from www.rethink.org/publications/pdfs/cues.pdf

Salkind, N. J. (2010). Encyclopaedia of research design. Thousand Oaks, US: Sage Publishing.

Slade, M. (2009). Personal recovery and mental illness: A guide for mental health professionals. Cambridge, UK: Cambridge University Press.

Slade, M., Bird, V., Le Boutillier, C., Williams, J., McCrone, P., \& Leamy, M. (2011). REFOCUS Trial: Protocol for a cluster randomised controlled trial of a pro-recovery intervention within community based mental health teams. BMC Psychiatry, 11, 185.

Slade, M., Phelan, M., Thornicroft, G., \& Parkman, S. (1996). The Camberwell Assessment of Need (CAN): Comparison of assessments by staff and patients of the needs of the severely mentally ill. Social Psychiatry, 31, 109-113.

Slade, M., Thornicroft, G., Loftus, L., Phelan, M., \& Wykes, T. (1999). CAN: The Camberwell Assessment of Need. London, UK: Gaskell.

Stephens, M. A. (1974). EDF statistics for goodness of fit and some comparisons. Journal of American Statistical Association, 347, 730-737.

Think Local Act Personal. (2015). Delivering care and support planning: Supporting implementation of the Care Act 2014. London, UK: DH, ADASS \& LGA.

Thornicroft, G. (2006). Shunned: Discrimination against people with mental illness. Oxford, UK: Oxford University Press.

Turner-Crowson, J., \& Wallcraft, J. (2002). The recovery vision for mental health services and research: A British perspective. Psychiatric Rehabilitation Journal, 25(3), 245-254.

Tyree, M., Kendrick, M. J., \& Block, S. (2011). Strengthening the role of the employee: An analysis of supported employment using social role valorization theory. Journal of Vocational Rehabilitation, 35, 197-209.

Walker, L., Perkins, R., \& Repper, J. (2014). Creating a recovery focused workforce: Supporting staff wellbeing and valuing the expertise of lived experience. Mental Health and Social Inclusion, 18(3), 133-141.

Wilkinson, R., \& Marmot, M. (Eds.). (2003) Social determinants of health: The solid facts ( $2 \mathrm{nd}$ ed.), Copenhagen, Denmark: World Health Organization.

Wilson, C., \& Secker, J. (in press). Validation of the Social Inclusion Scale with students. Social Inclusion, 3.

Wolfensberger, W. (1983). Social role valorisation: A proposed new term for the principle of normalisation. Mental Retardation, 21(6), 234-239. 


\section{About the Authors}

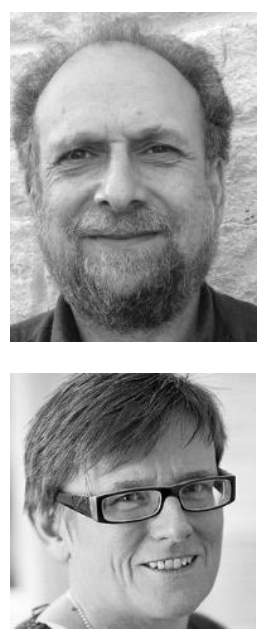

\section{Dr. Fabian Davis}

Fabian Davis was until recently a Consultant Clinical Psychologist for Oxleas NHS Foundation Trust in London. He is an Academic Associate of the Centre for Citizenship and Community at UCLAN. He was previously an Associate Director of the National Social Inclusion Programme at the Department of Health and is now an independent consultant. His doctoral research was a collaboration with expert service users on social exclusion and recovery in mental health.

\section{Dr. Jan Burns}

Jan Burns is a Professor of Clinical Psychology and Head of the School of Psychology, Politics and Sociology at Canterbury Christ Church University. Her research interests include disability, identity, gender and more recently Paralympic inclusion. 